\title{
Environmental Assessment of Heavy Metal Pollution in Bottom Sediment of Eastern Alexandria Harbour, Egypt
}

\author{
Abdul Ghani A. Rashed ${ }^{1}$, Mahmoud S. Ibrahim², Maie I. El-Gammal², Amr Z. Hamoda ${ }^{3}$ and Omnya \\ A. El-Batrawy*2 \\ ${ }^{1}$ High Institute in Souq Al-Khamis, Tripoli, Libya. \\ ${ }^{2}$ Environmental Sciences Department, Faculty of Science, Damietta University. \\ ${ }^{3}$ Marine Geophysics, National Institute of Oceanography and Fisheries, Alexandria.
}

Received: 10 October 2017 /Accepted: 2 December 2017

* Corresponding author: mgammal147@yahoo.com

\begin{abstract}
In this study, the concentrations of heavy metals were measured in the sediment of the Eastern Alexandria Harbour collected twice during 2016. The range and average concentrations measured in ppm were (ND-2775.93) (1592.59) for Fe and (13.90 - 235.73) (71.36) for Zn, (ND - 8.77) (3.93) for $\mathrm{Ni}$ and (6.35 - 42.99) (25.04) for Cr. For clarity, Enrichment factor index (EF) was used to determine the level of sediment contamination. The pollution load index (PLI) calculated for all the sediment samples that fall in the second terminology $(1<\mathrm{CF}<3$, moderate contamination factor) except sample (10 and 12) that fall in the first terminology $(\mathrm{CF}<1$, low contamination factor). Results of geoaccumulation index (Igeo) calculations in samples for the back ground values $100 \%$ of samples fall in class (0) for all the heavy metals ( $\mathrm{Fe}, \mathrm{Mn}, \mathrm{Ni}$ and $\mathrm{Cr}$ ). So, sediment is not enriched by these metals. while the results of geoaccumulation index (Igeo) calculations for Zn, it indicated that there is $91.4 \%$ of the samples fall in class (0) unpolluted) with no polluting effect to the environment. While $8.3 \%$ fall in class (1) (from unpolluted to moderately polluted). This was recorded at sample (8). It was recorded 0.31 that collected from the North-west of the harbour which is very active area. Sediment Quality Assessment, metal concentrations in the sediments of the samples was as high as above (ERM) values. All the samples fall in the range below (ERL) for both of $\mathrm{Ni}$ and $\mathrm{Cr}$. And most of the samples fall in the range below (ERL) for $\mathrm{Zn}$ in (11) sample. While, sample (1) only fall in the range between $(E R L$ and $E R M)$ for $\mathrm{Zn}$. The bottom sediments serve as a reservoir for heavy metals and therefore deserve special consideration in the planning and design of aquatic pollution research studies.
\end{abstract}

Keywords: Eastern Alexandria Harbour, Heavy metals, Pollution indices, Sediments.

\section{Introduction}

Aquatic systems are very sensitive to heavy metal pollutants as they are not usually eliminated either by biodegradation or by chemical means, in contrast to most organic pollutants. The gradual increase in the metal levels in aquatic environment is mainly due to anthropogenic sources. In addition, the decay of organic materials in aquatic systems together with detritus formed by natural weathering processes provides a rich source of nutrients in both the bottom sediment and overlying water body. 
Microorganisms, microflora and algae are capable of incorporating and accumulating metals in to their living cells from various supply sources. Consequently, small fish become enriched with the accumulated substances. Eventually man, consuming the fish, inevitably suffers from the results of an enrichment taken place at each trophic level, where less is extracted than ingested (Forstner and Wittmann, 1983; Yang et al., 2012).

Marine sediments can be sensitive indicators for monitoring contaminants in aquatic environments (Pekey et al., 2004) .The bottom sediments serve as a reservoir for heavy metals and therefore deserve special consideration in the planning and design of aquatic pollution research studies. If a sufficiently large and stable sediment sink can be located and studied, it will allow the investigators to evaluate the geochemical changes over time and possibly to establish baseline levels against which current conditions can be compared and contrasted. Heavy metals, such as mercury, cadmium, lead, zinc and copper, are regarded as serious pollutants of aquatic ecosystems because of their environmental persistence, toxicity and ability to be incorporated into food chains.

Marine sediments of the Mediterranean coast of Egypt have been polluted with various kinds of hazardous and toxic substances as a result of industrial development and different anthropogenic activities and the surface of sediments contains various kinds of heavy metals and other elements beyond the natural levels, that is, back ground values, (Abdallah, 2007; El Nemr et al., 2007).

The studies on heavy metals can be important in two main aspects. First, from the public health point of view, where the attention has been drawn to the necessity of measuring the accumulation of heavy metals; particularly these metals which pose serious health hazards to humans (e.g. Cadmium, Lead, and Mercury). Second, from the aquatic environment view point, the main problem had been to prevent biological deterioration and to identify the sources which threaten ecological equilibrium. In this regard, the more abundant metals such as copper, zinc and manganese may sometimes represent greater hazard than lead, mercury and cadmium (Kinne, 1984).

Egypt has about $(1050 \mathrm{~km})$ of coastline along the Mediterranean Sea, which is of great environmental, economic and recreational value. Some of these coastal areas especially in front of the large cities receive different types of pollution sources (El-Moselhy et al., 2016). The aim of the present study is to assess the distribution of heavy metals ( $\mathrm{Fe}, \mathrm{Zn}, \mathrm{Ni}$ and $\mathrm{Cr}$ ) in the sediment of the Eastern Alexandria Harbour and to evaluate the contamination levels of the Eastern Harbour of Alexandria.

\section{Materials and Methods}

Study Area

The Eastern Harbour of Alexandria is a shallow, semi-enclosed protected embayment occupying the central part of the coast of Alexandria with about $(750 \mathrm{~m})$ meter in length. The Harbour area lies between latitudes $\left(31^{\circ} 12^{\prime}\right.$ to $\left.31^{\circ} 13^{\prime}\right) \mathrm{N}$ and longitudes $\left(29^{\circ} 53^{\prime}\right.$ to $\left.29^{\circ} 54^{\prime}\right) \mathrm{E}$. The exchange between the Harbour water and the Mediterranean water takes place through two main openings, the western known as El-Boughaz and the eastern known as El-Silsila (Fig.1). The overall area covers about $\left(2.53 \times 10^{3} \mathrm{~m}^{2}\right)$ with an average depth of $(6 \mathrm{~m})$ with maximum depth of about (12m) (EL-Rayis et al., 1997; EL-Sabrouti et al., 1997 and AbdAllah, 2007). The study area is used for fishing activities, Yachts sports, boat building and recreation. The Katey Bey is directly affected by sewage discharge from a sewer of the adjacent $\mathrm{Al}$ Anfoushi area, and both Eastern Harbour and Katey Bey indirectly affected by different discharged wastes from El-Umoum Drain to El Mex Bay west of the study area.

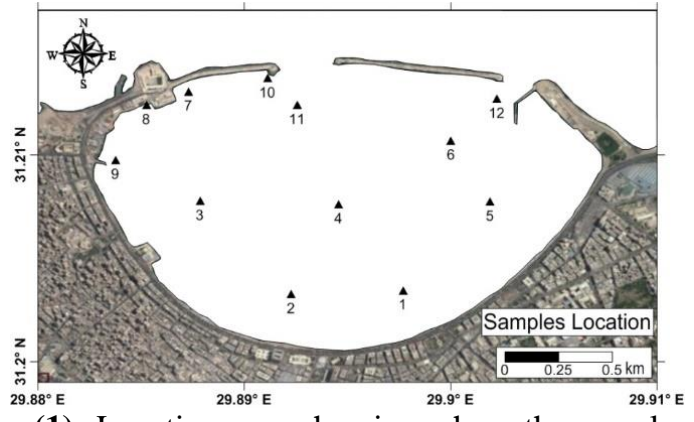

Fig. (1): Location map showing where the samples of sediments were collected in the study area.

\section{Sediment Sampling and Analysis}

About half $(\mathrm{kg})$ of sediment samples were collected twice during 2016 from (12) locations adequately covering the different regions in the Eastern harbor (Fig.1 and Table 1). The samples were sliced from the grab center, using a plastic spoon to avoid contamination by the metallic part of the grab and placed in self- sealed polyethylene bags for copper determination, which were 
previously washed $(1: 1 \mathrm{HCl})$ and rinsed with metal free water. The location was determined using a Geological Positioning System (GPS) sites were chosen to cover areas which are known to be affected by land-based activities.

Table 1: Sample locations of sediment samples collected from Eastern Harbour.

\begin{tabular}{c|c|c}
\hline $\begin{array}{c}\text { Site } \\
\text { no }\end{array}$ & $\begin{array}{c}\text { Latitude } \\
\mathbf{N}\left({ }^{\circ}\right)\end{array}$ & $\begin{array}{c}\text { longitude } \\
\mathbf{E}\left({ }^{\circ}\right)\end{array}$ \\
\hline $\mathbf{1}$ & 31.20340 & 29.89769 \\
\hline $\mathbf{2}$ & 31.20322 & 29.89227 \\
\hline $\mathbf{3}$ & 31.20773 & 29.88785 \\
\hline $\mathbf{4}$ & 31.20757 & 29.89457 \\
\hline $\mathbf{5}$ & 31.20770 & 29.90192 \\
\hline $\mathbf{6}$ & 31.21065 & 29.90002 \\
\hline $\mathbf{7}$ & 31.21302 & 29.88729 \\
\hline $\mathbf{8}$ & 31.21236 & 29.88526 \\
\hline $\mathbf{9}$ & 31.20971 & 29.88375 \\
\hline $\mathbf{1 0}$ & 31.21366 & 29.89112 \\
\hline $\mathbf{1 1}$ & 31.21237 & 29.89257 \\
\hline $\mathbf{1 2}$ & 31.21266 & 29.90224 \\
\hline
\end{tabular}

The samples were spread in the laboratory on plastic sheets for a few days at room temperature inside a clean cabinet until dryness to constant weight. They were sieved through $(2 \mathrm{~mm})$ sieve to get rid of gravel. Then each sample was divided into two subsamples. One of the subsamples is used for the grain size analyses, while the other subdivision was homogenized using an agate mortar in order to normalize the variation in grain size of the sediments in the sample.and kept in clean well-stoppered polyethylene containers until analysis.

\section{Grain Size Analysis}

About (18-32gm) of dried samples was taken for mechanical analysis. The samples were subjected to the combined technique of dry sieving and pipette analysis according to the method described by (Folk, 1974). Grain size determination was made on the dried samples by the conventional sieving method. Dry sand was fractioned by dry sieving using sieves with openings of $(2,1,0.5,0.25,0.125,0.063$ and 0.032 $\mathrm{mm})$ and an electric shaker, and the pipette analysis technique was used for separation of sand, silt and clay fractions to illustrate the sediment types.

\section{Total Organic Carbon}

Total organic carbon (TOC) was determined according to the method described by (Gaudette and Flight, 1974). The total concentrations of heavy metals (iron, zinc, nickel and chromium) in the samples were digested with a mixture of concentrated $\left(\mathrm{HNO}_{3} / \mathrm{HClO}_{4} / \mathrm{HF}\right)$ (6:3:1) according to (Oregioni and Aston, 1984).

\section{Environmental Indicators}

Enrichment Factor (EF), Pollution Load Index (PLI), and Geo-accumulation Index $\left(\mathrm{I}_{\text {geo }}\right)$ were used to evaluate the degree of contamination in the sediments.

\section{Enrichment Factor (EF)}

According to (Ergin et al., 1991) the metal enrichment factor (EF) is calculated using the following equation:

$$
\mathrm{EF}=(\mathrm{M} / \mathrm{Fe})_{\text {sample }} /(\mathrm{M} / \mathrm{Fe}) \text { Background }
$$

Elements can be divided in to three major groups with respect to their corresponding enrichment factor. Elements without enrichment $(\mathrm{EF}<10)$, elements with medium-level enrichment $(10>\mathrm{EF}$ $<100)$ and finally highly enriched elements (EF > 100).

\section{Pollution Load Index (PLI)}

Pollution load index (PLI) was computed according to (Tomolison et al., 1980) using the following equation:

$$
\mathrm{PLI}=(\mathrm{CF} 1 \times \mathrm{CF} 2 \times \ldots \ldots \ldots . \mathrm{CF} n)^{1 / \mathrm{n}}
$$

Where $\mathrm{CF}$ is Contamination factor which is equal to the concentration of the metal in sediment sample divided by its background concentration $\mathrm{N}$ is number of metals investigated.

The following terminologies are used to describe the contamination factor: $(\mathrm{CF}<1)$ low contamination factor; $(1<\mathrm{CF}<3)$ moderate contamination factor; $(3<\mathrm{CF}<6)$ considerable contamination factor and $(\mathrm{CF}>6)$ very high contamination factor (Saleh, 2006).

\section{Geoaccumulation Index (Igeo)}

Geoaccumulation index (Igeo) has been calculated for analyzed metals. It was originally defined by (Müller, 1979). In order to determine and define metals contamination in sediments, by comparing current concentrations with preindustrial levels. It was also to clarify the extent of heavy metals contamination associated with the sediments and can be calculated by the following 
equation:

$$
\text { Igeo }=\log _{2}[\mathrm{Cx} /(1.5 \mathrm{Bx})]
$$

Where $\mathrm{Cx}$ is the measured concentration of the examined metal " $x$ " in the sediment, $B x$ is the geochemical background concentration of the metal "x". Factor 1.5 is the background correlation factor due to lithogenic effects.

\section{Results and Discussion}

\section{Grain Size Analysis}

The grain size analysis for the collected samples were shown in Table (2). Most of the samples were characterized by high percentage of sand ranging from $(96.02 \%)$ in sample (6) to $(100 \%)$ in samples (11 and 12) which are sandy sediments due to high sand percentage. While, the silt percentage was high only in sample (4) dominated by $(53.04 \%)$ showing coarse silt sediment texture . Apparently, sampling station no. 3 was characterized by the presence of rocks "gravel". Obviously, the dominance was sandy sediments in most stations. It was observed that the sediments samples no. (11 and 12) contained appreciable amounts of tubeworm skeletons of some calcareous organisms, gastropod shell fragments.

Table 2: Sample locations, depth and grain size of sediment samples collected from Eastern Harbour.

\begin{tabular}{c|c|c|c|c|l}
\hline Site no & $\begin{array}{c}\text { Depth } \\
(\mathbf{m})\end{array}$ & $\begin{array}{c}\text { Sand } \\
(\boldsymbol{\%})\end{array}$ & $\begin{array}{c}\text { Silt } \\
(\boldsymbol{\%})\end{array}$ & $\begin{array}{c}\text { Clay } \\
(\boldsymbol{\%})\end{array}$ & Nomenclature \\
\hline 1 & -5 & 97.82 & 2.18 & 0 & Fine sand \\
\hline 2 & -3 & 99.76 & 0.24 & 0 & Coarse sand \\
\hline 3 & -4 & 0 & 0 & 0 & Rock \\
\hline 4 & -6 & 44.85 & 53.04 & 2.11 & Coarse silt \\
\hline 5 & -5 & 99.03 & 0.97 & 0 & Medium sand \\
\hline 6 & -7 & 96.02 & 3.98 & 0 & Fine sand \\
\hline 7 & -5 & 99.07 & 0.93 & 0 & Medium sand \\
\hline 8 & -6 & 99.82 & 0.18 & 0 & Coarse sand \\
\hline 9 & -5 & 99.88 & 0.12 & 0 & Coarse sand \\
\hline 10 & -6 & 99.49 & 0.51 & 0 & Medium sand \\
\hline 11 & -6 & 100 & 0 & 0 & Coarse sand \\
\hline 12 & -6 & 100 & 0 & 0 & Very Coarse sand \\
\hline Min & & 44.85 & 0 & 0 & \\
\hline Max & & 100 & 53.04 & 2.11 & \\
\hline Average & & 90.82 & 8.86 & 0.32 & \\
\hline & & & & & \\
\hline
\end{tabular}

\section{Total Organic Carbon (TOC \%)}

The total organic carbon (TOC \%) of the sediments samples were shown in Table (3). The total organic carbon in the sediment samples were ranging from $(0.43 \%)$ in sample (2) to $(2.3 \%)$ in sample (4). The lowest concentration level of (TOC \%) was recorded in samples $(2,12,5,8,1$, and 11$)$ and were as follow $(0.43,0.49,0.62,0.8$,
$0.8, \quad 0.84, \quad 0.87 \%)$ respectively. These low percentages were due to the structure of the sediments in this area which was mainly coarse sand that had low affinity to absorb organic matter. But the sediment samples $(7,10,6$, and 3) were characterized by moderate TOC $\%$ of about (1.27, $1.47,1.50,1.59 \%)$, respectively. These moderate percentages were due to the structure of the sediments of these samples which were mainly medium and fine sand. The highest TOC\% was about $(2.3 \%)$ that was determined in sediment sample (4). This sample was characterized by high percentage of silt which had high affinity to organic matter. Where (Zhang et al., 2007) stated that organic matter increased with the decrease of grain size and attributed this to the protective action of silt. Sediments with fine particles provide better surface areas for pollutants to adsorb than those with coarse particles (Adesuyi, 2016).

Table 3: concentration of total organic carbon (TOC) and heavy metal (ppm) of sediment samples collected from Eastern Harbour.

\begin{tabular}{c|c|c|c|c|c}
\hline Site no & $\begin{array}{c}\text { TOC } \\
\text { \% }\end{array}$ & $\begin{array}{c}\text { Fe } \\
\mathbf{p p m}\end{array}$ & $\begin{array}{c}\mathbf{Z n} \\
\mathbf{p p m}\end{array}$ & $\begin{array}{c}\text { Ni } \\
\mathbf{p p m}\end{array}$ & $\begin{array}{c}\mathbf{C r} \\
\mathbf{p p m}\end{array}$ \\
\hline 1 & 0.84 & 447.9 & 20.60 & $\mathrm{ND}$ & 42.43 \\
\hline 2 & 0.43 & 2297.88 & 24.32 & 6.98 & 27.74 \\
\hline 3 & 1.59 & 2201.61 & 39.47 & 5.56 & 22.72 \\
\hline 4 & 2.30 & $\mathrm{ND}$ & 67.52 & 8.77 & 35.03 \\
\hline 5 & 0.62 & 1482.23 & 31.15 & 5.80 & 23.56 \\
\hline 6 & 1.50 & 2775.93 & 61.65 & 5.97 & 22.31 \\
\hline 7 & 1.27 & 2511.01 & 65.99 & 4.89 & 24.42 \\
\hline 8 & 0.80 & 1733.27 & 235.73 & $\mathrm{ND}$ & 20.60 \\
\hline 9 & 0.80 & 2016.13 & 142.58 & $\mathrm{ND}$ & 15.66 \\
\hline 10 & 1.47 & 541.93 & 28.39 & $\mathrm{ND}$ & 6.35 \\
\hline 11 & 0.87 & 1741.11 & 18.07 & 5.51 & 42.99 \\
\hline 12 & 0.49 & 89.36 & 13.90 & 2.8 & 17.43 \\
\hline Min & 0.43 & $\mathrm{ND}$ & 13.90 & $\mathrm{ND}$ & 6.35 \\
\hline Max & 2.3 & 2775.93 & 235.73 & 8.77 & 42.99 \\
\hline Average & 1.12 & 1592.60 & 71.3581 & 3.94 & 25.04 \\
\hline
\end{tabular}

\section{Total Heavy Metals}

$\operatorname{Iron}(\mathrm{Fe})$ :

The total iron concentration in the Eastern harbor sediment samples were shown in Table (3). The minimum iron concentration was (89.36 ppm) that detected at the eastern entrance of the harbour (Elsilsila) at Station (12), that lies at the out let of the harbour where it is fare from any source of pollution that may increase the iron concentration in the sediments. So, this sample acts as a reference sample. In addition, this may be attributed to the high percentage of sand content (100\%) (Very coarse sand), as well as the low percentage of TOC\% $(0.49 \%)$. On the other hand, the maximum $\mathrm{Fe}$ concentration was (2776 ppm) 
and detected at the east part of the harbour at Station (6). Although that sample was taken from an area that is relatively away from sources of pollution it recorded the highs iron concentration. Although both of the samples (12 and 6) are near to each other the $\mathrm{Fe}$ concentrations recorded were extremely different.

The results revealed that there is a high enrichment by iron at the Eastern Harbour detected in stations $(6,7,2,3,9,11,8$ and 5) $(2775.93,2511.01,2297.88,2201.61,2016.13$, $1741.11,1733.27,1482.24 \mathrm{ppm})$ respectively. While, the concentrations of iron in the studied samples $(4,12,1$ and 10) were (ND, 89.36, 447.97, 447.97ppm) respectively. The high contents are attributed to the human activities accompanied with increase of the amount domestic discharge from boats and fishing activities, fueling and maintenance practices. The sediment acts as a major sink for pollutants in the aquatic environment where the suspended sediment particles settle the adsorbed pollutants to be removed from the water column. Generally, the course of oxidation for iron is affected by many factors, (e.g. pH, temperature) (El-Geziry et al., 2007).

The results obtained in this study were compatible with Hamed et al., ( 2012) study of the bottom sediment in the Egyptian coastal, which ranged from (1748.2-2030 $\left.\mathrm{mg} \mathrm{kg}^{-1}\right)$, and to some extent with AbdelGhani et al., (2013) study in the Eastern Harbor which ranged from ( $10-$ $\left.30240 \mathrm{mg} \mathrm{kg}^{-1}\right)$ and an average $\left(12946 \mathrm{mg} \mathrm{kg}^{-1}\right)$. The maximum concentration of total iron less than two times than that recorded in the sediment Eastern Harbor $\left(3,351.8 \mathrm{mg} \mathrm{kg}^{-1}\right.$; El-Nemr et al., 2007) And much lower than those recorded in the sediment Damietta Harbor which ranged from (14216- 55619 ppm; El-Gharapawy, 2013), and of that reported in sediments of NW Spain $(22,970$ $\mathrm{mg} \mathrm{kg}{ }^{-1}$; Villares et al., 2003).

\section{Zinc $(Z n)$}

Zinc concentrations in the Eastern harbor were ranged from (13.90 to $235.73 \mathrm{ppm}$ ) in all the analyzed samples (Table 3).The average of zinc concentration was about (71.36ppm).

The minimum zinc concentration determined was $(13.90 \mathrm{ppm})$ at the eastern outlet of the harbor (Elsilsila) at Station (12). This may be attributed to the high percentage of sand content of that sample which equals (100\%) (Very coarse sand), as well as the low percentage of total organic carbon (TOC \%) content $(0.49 \%)$. On the other hand, the maximum zinc concentration determined was about (235.73ppm) at the western part of the harbor Station (8). Although that Station characterized by high percentage of sand content (99.82\%) (Coarse sand) it recorded the maximum zinc concentration. This elevated concentration of heavy metal in coarse grains is most probably accounted for the inclusion of fine metalliferous particles on the surface of large particles, or to ineffective particles separation (Idris et al., 2007).

In addition to the western part of the harbor at stations (8 and 9) record maximum concentration due to sewage central part of the city of Alexandria, this was pumped to this area in the past. The Eastern Harbour is mainly along its south and southwest inner margin influenced by sewage disposal of the central part of Alexandria City, which is pumped into the Mediterranean Sea. The main sewage tube begins at Kayet Bay Pumping Station, which is the main metropolitan sewage pumping station of the central part of Alexandria. It discharged to the sea about $\left(96 \times 10^{6}\right.$ $\mathrm{m}^{3} / \mathrm{yr}$ ) during (1985-1986) as reported by (Abu-El Kassem, 1987). Besides, small (11) sewage openings discharged untreated sewage wastes directly to the harbor in winter and summer, respectively. Also, large quantities of different wastes of the fishing and sailing boats anchoring inside the harbor were dumped into its northwestern part. Also this elevated level of zinc may be resulted from the release of zinc from the extensive use of anti-fouling paints by shipping activities.

The results revealed that there is a high contamination by zinc at Eastern Harbor at Station $(12,11,1,2,10,5,3,6,7,4,9$ and 8) (13.90, $18.07,20.60,24.32,28.39,31.16,39.47,61.65$, $65.90,67.53,142.58,235.73 \mathrm{ppm})$ respectively. These samples show high zinc concentrations due to the harbor activities such as loading and off loading of goods, cleaning of ballasting, fueling and maintenance practices.

Through the results obtained in this study show that they are compatible with concentration of total zinc that recorded in the sediment along Mediterranean coast of Egypt [El Mex, NIOF, Shatby, El Mamourah, Western Harbour, Gleem, Abu Quir Bay, Montazah and Eastern Harbour $(100.55,63.29,47.74,141.92, \quad 20.92,47.58$, $127.36,166.54,126.6 \mathrm{ppm}$ ) respectively; (ElNemr et al., 2007), and in bottom samples the range (53.35-198.29 \& average 146.05 ppm; ElGharapawy, 2009) in Damietta Harbour. and (25-126 in Rosetta \& 46-93 in Damietta; El- 
Gharapawy, 2013); and an average $(95.25 \mathrm{mg} \mathrm{kg}$ '; Atta and Zakaria, 2014) in sediment samples along the Alexandria Coastline and an average (107 $\mathrm{mg} \mathrm{kg}^{-1}$; Ramessur, 2004) in the western coast of Mauritius.

Nickel (Ni)

Nickel concentrations were ranged from (ND to $8.77 \mathrm{ppm}$ ) in all the analyzed samples (Table 3). The average of nickel concentration equals $(3.93 \mathrm{ppm})$. The results revealed that the sediment texture affect the accumulation of $\mathrm{Ni}$ in the sediments. The maximum $\mathrm{Ni}$ concentration where recorded at station (4) that was mainly composed of silt and had the maximum TOC\%. Also, this elevated level of $\mathrm{Ni}$ may be resulted from the release of $\mathrm{Ni}$ from the disposal of liquid effluents from the ships, as well as, the atmospheric deposition (Mucha et al., 2003). While, was (ND) at samples (1, 8, 9 and 10) as these samples were composed mainly of sand.

Through the results obtained in this study show that they are compatible with concentration of total nickel that recorded in the sediment samples an average (3.81 mg kg-1) in the Eastern Harbour (1.59 $\mathrm{mg} \mathrm{kg}^{-1}$ ) in Abu Quir Bay (Khalil and Rifaat, 2010).

The results of the total nickel concentration in sediment samples were lower than that recorded in sediment samples along Mediterranean coast of Egypt [El Mex, Western Harbour, Eastern Harbour, Shatby, SidiBishr , Abu Quir Bay and Rasheed (98.82, 72.59, 154.3, $86.21,54.45,40.65,58.34 \mathrm{ppm}$ ) respectively; (ElNemr et al., 2007); and an average in sediment samples $\left(35.77 \mathrm{mg} \mathrm{kg}^{-1}\right.$; Atta and Zakaria, 2014) in along the Alexandria Coastline. and in bottom samples the range (0-97.41 \& average 41.32 ppm; El-Gharapawy, 2009) in Damietta Harbour. and (18-71 in Rosetta \& 23-76 in Damietta; ElGharapawy, 2013) and an average in sediment samples (32.75 $\mathrm{mg} \mathrm{kg}^{-1}$; Khalil and Rifaat, 2010) in the Eastern Harbour in sediment of Ria Ferrol (NW Spain) were in the range (11.3-67.2 $\mu \mathrm{g} \mathrm{g}^{-1} \&$ an average $32 \mu \mathrm{g} \mathrm{g}^{-1}$; Barciela et al., 2003).

\section{Chromium $(\mathrm{Cr})$}

Chromium concentrations were ranged from $(6.35$ and $42.99 \mathrm{ppm})$ in all the analyzed samples (Table 3). The average of nickel concentration equals $(25.04 \mathrm{ppm})$. The minimum chromium concentration recorded (6.35 ppm) was at Station (10). This is mainly related to the sediment texture which is dominantly sand $(99.49 \%)$. While the maximum chromium concentration recorded $(42.99,42.43 \mathrm{ppm})$ were at Stations (11 and 1) respectively. This elevated chromium concentration may be attributed to atmospheric deposition as well as the industrial inputs from different harbor activities (Rigollet $\boldsymbol{e} t$ al., 2004).In addition, the Eastern Harbour is mainly influenced by several kinds of human activities including fishing, yacht sport, landbased effluents, boat building workshops, recreation and sailing boats anchoring inside the Harbour were dumped into its northwestern part(Saad and Shreadah, 1984).These wastes include chromium which was recorded in several marine organisms (AboulDahab et al., 1990, Barakat 2004 and El-Naggar et al., 2014).

Through the results obtained in this study show that they are compatible with concentration of total chromium that recorded in the sediment along Mediterranean coast of Egypt (Sidi Kerir, El Mex, Western Harbour, Eastern Harbour, Sidi Gaber and Abu Quir Bay (11.58, 16.08, 19.29, 45, 28.94, $18.01 \mu \mathrm{g} / \mathrm{g}$ ) respectively; (El-Nemr et al., 2007). and an average in sediment samples (5.42 $\mathrm{mg} \mathrm{kg}$; (Abou-Taleb, 2004) in the Eastern Harbour. and in sediment samples the range (N.D39 and an average (27.91ppm); Abdallah, 2007) in the Eastern Harbour. and an average in sediment samples an average $(18.47 \mu \mathrm{g} / \mathrm{g}$; Salem et al., 2014) in surface sediment samples collected from the Suez Gulf, Aqaba Gulf and the Red Sea. While the concentration of chromium was higher (44$274 \&$ an average 150ppm; El-Gohary et al., 2012) in Aby-Qir Bay. and an average in sediment samples an average $\left(72.33 \mathrm{mg} \mathrm{kg}^{-1}\right.$; Atta and Zakaria, 2014) in along the Alexandria Coastline and in sediment samples the range (30 to over 200 $\mu \mathrm{g} / \mathrm{g}^{-1}$ ) in UK estuarine sediments (Murray et al., 1983).

\section{Environmental Indicators}

\section{The Enrichment Factor}

In the present study, $\mathrm{Fe}$ has been used to calculate the enrichment factor. $\mathrm{Fe}$ is an abundant element in the structure of clay minerals and is also associated with particle surfaces as oxide coatings. Iron $(\mathrm{Fe})$ in the estuarine sediment is mainly from natural weathering processes and has been broadly used to normalize the metal concentrations in order to reduce particle grain size influence (e.g., Daskalakis and $\mathbf{O}^{\prime}$ Conor, 
1995 and Feng et al., 1998).Therefore, it is believed that, it is reasonable to use Fe to calculate metal enrichment factor. In fact, several authors have successfully used iron to normalize heavy metals contaminants (Feng et al., 1998 and Mucha et al., 2003).

The enrichment factor calculations for Manganese (Mn) in samples were shown in Table (4). All the samples recorded without enrichment except sample (12) that collected from the north eastern entrance to harbor. It recorded (13.38) medium-level enrichment, which is very near to 10 in range. So, Manganese in that area was not harmful.

Table 4: Calculated enrichment factor and Pollution Load Index for sediment samples

\begin{tabular}{c|c|c|c|c|c}
\hline Stations & EF-Mn & EF-Zn & EF-Ni & EF-Cr & PLI \\
\hline 1 & 3.30 & 13.14 & ND & 47.35 & 1.01 \\
\hline 2 & 3.16 & 3.03 & 2.14 & 6.05 & 1.03 \\
\hline 3 & 2.91 & 5.11 & 1.79 & 5.15 & 1.04 \\
\hline 4 & ND & ND & ND & ND & 1.16 \\
\hline 5 & 3.95 & 6.01 & 2.79 & 7.95 & 1.04 \\
\hline 6 & 2.02 & 6.34 & 1.50 & 4.00 & 1.12 \\
\hline 7 & 1.87 & 7.51 & 1.36 & 4.85 & 1.09 \\
\hline 8 & 1.37 & 38.86 & ND & 5.95 & 1.32 \\
\hline 9 & 1.94 & 20.20 & ND & 3.90 & 1.41 \\
\hline 10 & 2.43 & 14.97 & ND & 5.85 & 0.93 \\
\hline 11 & 3.46 & 2.97 & 2.29 & 12.35 & 1.03 \\
\hline 12 & 13.38 & 44.46 & 22.71 & 97.50 & 0.91 \\
\hline
\end{tabular}

The enrichment factors calculations for Zinc $(\mathrm{Zn})$ in samples were shown in table (4). The $\mathrm{Zn}$ values of enrichment factors revealed a maximum value (44.46) at Station (12) that collected from the north eastern entrance to harbor and a minimum value (2.97) at station (11) that collected from the western entrance to harbor. Half of the samples $(1,8,9,10$ and 12) recorded mediumlevel enrichment, while the other half of the samples $(2,3,5,6,7$ and 11) recorded without enrichment. Generally, the medium-level enrichment of $\mathrm{Zn}$ calculated in that area was with in the first (50\%) of the medium-level range, so zinc is not harmful in that area. This medium-level enrichment of zinc may be attributed to the release of $\mathrm{Zn}$ from different anthropogenic sources (Gohand and Chou, 1997) such as, sewage outfall and industrial effluents (Bothner et al., 1998).

The enrichment factors calculations for copper $(\mathrm{Cu})$ in samples were shown in Table (4) The $\mathrm{Cu}$ values of enrichment factors revealed a maximum value (112.22) at Station (9) that collected from the west side of the harbor recorded Highly enriched elements, While, the samples (1, $6,8,10$ and 12) recorded medium-level enrichment. On the other hand, the samples $(2,3$,
5, 7 and 11) recorded without enrichment. This might indicate that the Eastern harbour has heavy accumulations of $\mathrm{Cu}$, which apparently come from sewers that include industrial wastes.

The enrichment factor calculations for nickel (Ni) in samples were shown in table (4). All the samples recorded without enrichment except sample (12) that collected from the north eastern entrance to harbor. It recorded (22.71) mediumlevel enrichment, which is very near to (10) in range. So, nickel in that area was not harmful.

The enrichment factor calculations for chromium (Cr) in samples were shown in table (4). All the samples recorded without enrichment except samples (1, 11 and 12) they recorded $(47.35,12.35,97.5)$ respectively, medium-level enrichment. Sample (12) was very near to (100) in range. So, chromium in this sample was harmful.

\section{Pollution Load Index}

The pollution load index calculated for all the sediments samples (table 4) that fall in the second terminology $(1<\mathrm{CF}<3)$, moderate contamination factor except sample (10 and 12) that fall in the first terminology $(\mathrm{CF}<1)$, low contamination factor.

\section{Geoaccumulation index (Igeo)}

The Geoaccumulation index can assess to the estimation of these pollution process. Müller has distinguished seven classes of Geoaccumulation index (Müller, 1981). The highest class (class six) reflects 100-fold enrichment above the background values. Based on the index as presented in Table (5) for Eastern harbor sediment samples, the calculated geoaccumulation index (Igeo) indicated that (100\%) of the samples fall in class ( 0 ) for the heavy metals ( $\mathrm{Fe}, \mathrm{Mn}, \mathrm{Ni}$ and $\mathrm{Cr}$ ) table (3) respectively. So, Eastern harbor sediments are not contaminated by these metals.

Table 5: Calculated Geoaccumulation index for sediment samples of eastern harbour.

\begin{tabular}{c|c|c|c|c|c}
\hline \multirow{2}{*}{ Stations } & $\begin{array}{c}\text { Igeo - } \\
\text { Fe }\end{array}$ & $\begin{array}{c}\text { Igeo - } \\
\mathbf{M n}\end{array}$ & $\begin{array}{c}\text { Igeo - } \\
\mathbf{Z n}\end{array}$ & $\begin{array}{c}\text { Igeo - } \\
\text { Ni }\end{array}$ & $\begin{array}{c}\text { Igeo - } \\
\text { Cr }\end{array}$ \\
\hline 1 & -6.91 & -5.18 & -3.21 & ND & -1.33 \\
\hline 2 & -4.55 & -2.89 & -2.97 & -3.43 & -1.94 \\
\hline 3 & -4.61 & -3.07 & -2.27 & -3.75 & -2.23 \\
\hline 4 & $\mathrm{ND}$ & -2.77 & -1.50 & -3.09 & -1.60 \\
\hline 5 & -5.18 & -3.20 & -2.61 & -3.69 & -2.18 \\
\hline 6 & -4.28 & -3.26 & -1.63 & -3.65 & -2.25 \\
\hline 7 & -4.42 & -3.52 & -1.53 & -3.94 & -2.12 \\
\hline 8 & -4.96 & -4.50 & 0.31 & $\mathrm{ND}$ & -2.37 \\
\hline 9 & -4.74 & -3.78 & -0.42 & $\mathrm{ND}$ & -2.77 \\
\hline 10 & -6.63 & -5.35 & -2.75 & $\mathrm{ND}$ & -4.07 \\
\hline 11 & -4.95 & -3.16 & -3.40 & -3.77 & -1.31 \\
\hline 12 & -9.20 & -5.50 & -3.78 & -4.72 & -2.61 \\
\hline
\end{tabular}


On the other hand, the geoaccumulation index (Igeo) for Zinc was shown in Table (5). All the samples fall in class (0) unpolluted) with no polluting effect to the environment except sample (8) fall in class (1) (from un polluted to moderately polluted), that collected from the North-west of the harbor which is very active area. Generally, these moderately polluted values of zinc may be attributed to the release of $\mathrm{Zn}$ from the anti-fouling paints on ships, as well as other anthropogenic sources such as, sewage outfall and industrial effluents.

The geoaccumulation index (Igeo) for Copper was shown in Table (5). Ten sediment samples fall in class (0) (un polluted). While, one sample fall in class (1) (from unpolluted to moderately polluted) and another sample fall in class (3) (From moderately to strongly polluted). They recorded $(0.99,2.08)$ respectively. These samples were (8 and 9) that collected from Northwest and West of the harbor, that both of them are active areas. All antifouling paints applied to commercial, naval and recreational vessels in the inner bay contain significant quantities of $\mathrm{Cu}$. Also these metals come from the effects of ships and boats gasoline combustion.

\section{Effect Range Low (ERL) and Effect Range Median (ERM) quotients}

The toxicity guidelines of heavy metals in sediments of samples are shown at Table (6). None of metal concentrations in the sediments of the samples was as high as above Effect Range Median (ERM) values. All the samples fall in the range below Effect Range Low (ERL) (12 samples) for both of $\mathrm{Ni}$ and $\mathrm{Cr}$. This is indicates that the sediments were rarely associated with biological effects. Most of the samples fall in the range below ERL for both $\mathrm{Zn}$ and $\mathrm{Cu}$ (11 and 10) samples respectively. Only (1 and 2) samples fall in the range between ERL and ERM for both $\mathrm{Zn}$ and $\mathrm{Cu}$, respectively.

Table 6: Toxicity guidelines of heavy metals ( $\mu \mathrm{g} g$ ${ }^{1}$,dry weight) in sediments of samples (Long $\boldsymbol{e t}$ al., 1995).

\begin{tabular}{l|l|l|l|l|l}
\hline Metal & ERL & ERM & $\begin{array}{c}\text { Below } \\
\text { ERL }\end{array}$ & $\begin{array}{c}\text { Between } \\
\text { ERL } \\
\text { \&ERM }\end{array}$ & $\begin{array}{c}\text { Above } \\
\text { ERM }\end{array}$ \\
\hline Zinc & 150 & 410 & 11 & 1 & $\ldots$ \\
\hline Nickel & 20.9 & 541.6 & 12 & $\ldots$ & $\ldots$ \\
\hline Chromium & 81 & 370 & 12 & $\ldots$ & $\ldots$ \\
\hline
\end{tabular}

ERL: Effect Range Low, ERM: Effect Range Median.

\section{References}

Abdallah, M.A.M. (2007): Accumulation and distribution of heavy metals in surface sediments of a semi enclosed basin in the southeastern Mediterranean sea, Egypt. Mediterranean Marine Science, 8 (1): 31-40.

Abdel Ghani, S, G., El, Zokm., A, Shobier., T, 'Othman. and M. Shreadah. (2013): Metal pollution in surface sediments of Abu-Qir Bay and Eastern Harbour of Alexandria, Egypt. Egyptian Journal of Aquatic Research. 39, 1-12. http://ees.elsevier.com/ejarwww.sciencedirect.com

AboulDahab, O., AN, Khalil \& Y, Halim. (1990): Chromium fluxes through Mex Bay inshore waters. Marine Pollution Bulletin 21(2): 68-73.

AboulKassim, T. A. (1987): Cycles of carbon, nitrogen and phosphorus in the marine environment in Alexandria region, M.Sc. Thesis, Alexandria University, $223 \mathrm{p}$.

Abou-Taleb, AmaalEid Abbas, (2004): Assessment of Some Heavy Metals and Their Accumulation in Some Marine Organisms in Alexandria Coastal Environmental. M.Sc. Thesis, Alexandria University.

Adesuyi, A. A., Ngwoke, M. O., Akinola, M. O., Njoku, K. L. and Jolaoso, A. O. (2016): Assessment of Physicochemical Characteristics of Sediment from Nwaja Creek, Niger Delta, Nigeria. Journal of Geoscience and EnvironmentProtection, 4, 16-27. http://dx.doi.org/10.4236/gep.2016.41002.

Atta, E. R. and Zakaria, Kh. M. (2014): Evaluation of Some Radioactive Materials and Heavy Metals in Marine Environment of Alexandria Coastline, Egypt. Journal of Environmental Protection, 5, 1618-1629. http://dx.doi.org/10.4236/jep.2014.517153.

Barakat, AO. (2004): Assessment of persistent toxic substances in the environment of Egypt. Environment International. 30(3): 309-322.

Barciela-Alonso, MC, Tubio-Franco MC and Prego, R. (2003): Nickel and cobalt determination in marine sediments by electrothermal atomic absorption spectrometry and their distribution in the Ria of Ferrol (NW Spain). Mar Pollut Bull 46:1504-1515.

Bothner, M. H., Buchhltzten, Brink, M., and Manheim, F. T. L. (1998): Metal Concentrations in surface sediments of Boston Harbor changes with time. Mar. Env. Res., vol. 45, pp. 17-55.

Daskalakis, K. D., and O' Connor, T. P. (1995): Normalization and elemental sediment contamination in the coastal United States. Environmental Science and Technology, vol. 29, pp. $470-477$.

El-Geziry, T. M.; AbdEllah, R.G., and Maiyza, I. A., (2007): Bathymetric chart of Alexandria Eastern Harbor. Egyptian Journal of Aquatic Research, 1687-4285 VOL. 33 NO. 1, 2007: 15-21.

El-Gharapawy, Suzan Mohamed, (2009): Assessment 
of Some Heavy Metals in the Bottom sediments in Damitta Harbor Egypt. M.Sc. Thesis Faculty of Science, Mansoura University.

El-Gharapawy, Suzan Mohamed, (2013): Geoenvironmental Assessment of the Mediterranean sediments in front of Rosetta and Damitta Branches - Egypt. Ph.D. Thesis Faculty of Science, Damitta University.

El-Gohary, Soaad El-Sayed, HermineRamzyZaki and Mona f. Elnaggar, (2012): Geochemical Study and Distrbution of some Trace Metals along Coastal Zone of Aby-Qir Bay, Mediterrnanean SeaAlexandria, Egypt. World Applied Sciences Journal, 18 (8):1011-1022,2012.

El-Moselhy, Kh. M.; Saad, E. M.; El-Shaarawy, R. F.; Mohamedein, L. I. and Mohmoud, S. A. (2016): Assessment of heavy metals pollution using sediments and bivalve Brachidontesvariabilis as bio indicators in the Gulf of Suez, Egypt. International Journal of Marine Science, 6(26): 1-13.

El-Naggar, MM, HAH Ibrahim, MG Battah. FKhAbd Al Gawad\& MS Ibrahim. (2014): Antifungal agent productionfrom a new marine Bacillus pumilus SMMH101. AfricanJournal of Microbiology 8(3): 286-296.

El-Nemr, A.M., El Sikaily, A. and Khaled, A. (2007): Total and leachable heavy metals in muddy and sandy sediments of Egyptian coast along Mediterranean Sea. Environmental Monitoringand Assessment, Vol. 129, pp.151-168.

EL-Rayis, O.A, Abouldahab, O.,Halim Y.\& Riley, J P., (1997): Levels of heavy metals in some food chain organisms from El-MexBay,west of Alexandria, Egypt. Proceedings of the.7th international conference on 'Environmental protection is a must' Alexandria University \&USPD,Alexandria, 20 - 22 May. pp. 26-35.

EL-Sabrouti, M.A., Bader EL-Din, A.M. \& ELSammak, A.A., (1997): Textural and chemical characteristics of the surfacial sediments in two coastal bays of Alexandria, Egypt. Proceedings of the. 7th international conference on 'Environment protection is a must'.Alexandria University \& USPD, Alexandria, 20 - 22 May. pp. 118 -130.

Ergin, M., Saydam, C., Bastürk, ö.,Erdem, E., and Yörük, R. (1991): Heavy metal concentrations in surface sediments from the two coastal inlets (Golden Horn Estuary and Izmit Bay) of the northeastern sea of Marmara. Chemical Geology, vol. 91, pp. 269-285.

Feng, H., Cochran, J. K., Liwiza, H., Brownawell, B., and Hischberg, D. J. (1998): Distribution of heavy metal and PCB contaminants in the sediments of an urban estuary: The Hudson River. Marine Environmental Research, vol. 45, pp. 69-88.

Folk, R. L. (1974): Petrography of sedimentary rocks. Univ. Texas, Hemphill, Austin, Tex., p.182.

Forstner, U and Wittmann, G.T.W. (1983): Metal pollution in the aquatic environment. SpringerVerlag, Berlin, pp. 30-61.
Gaudette, H. E. and Flight, W. R. (1974): An inexpensive titration method for the determination of organic carbon in recent sediments. Journal of sedimentary petrology. 44 (1), 249-253.

Gohand, B. P., and Chou, L.M. (1997): Heavy metal levels in marine sediments of Singapore. Environ. Monitor. Assess, vol. 44, pp.67-80.

Hamed, A., El-Serehy, HamdyAboulela; Fahad AlMisned; Mona Kaiser; Khaled Al-Rasheid1, and HebHamed, A., El-Serehy, HamdyAboulela; Fahad Al-Misned; Mona Kaiser; Khaled Al-Rasheid1, and HebaEzz El-Din. (2012): Heavy metals contamination of a Mediterranean Coastal Ecosystem, Eastern Nile Delta, Egypt. Turkish Journal of Fisheries and Aquatic Sciences 12: 75176.

Khalil. M. Kh and A. E. Rifaat, (2010): Enrichment of zink, copper, lead, and nickel in Bottom Sediment From Three Environmentally Different Regions off Alexandria, Egypt,National Institute of Oceanography and Fisheries Egyptian. Alexandria, Egypt.

Mucha, A. P., Vasconcelos, M. T. S. D. and Bordalo, A. A, (2003): Macro benthic community in the Douro Estuary: relations with heavymetals and natural sediment characteristics. Environmental Pollution,121,169-180.

Müller, G. (1979): Schwermrtalle in den sedimente des Rheins-Veranderungenseitt 1971. umschan, vol. 79, 778-783.

Müller, G. (1981): Die Schwermetallbeastung der sedimente des Neckars und seiner Nebenflusse: eineBestandsaufnahme. Chemical Zeitung, vol. 105, pp. 157-164.

Murray, JW., Spell, B., Paul, B. (1983): The contrasting geochemistry of manganese and chromium in the eastern tropical Pacific Ocean. In: Wong CS, Boyle E, Bruland KW, Burton JD, Goldberg ED (eds) Trace metals in sea water. Plenum Press, New York/London, 643-669.

Oregioni, B., Aston, S. R. (1984): The determination of selected trace metals in marine sediments by flame atomic absorption spectrophotometry. IAEA, 244, Monaco Laboratory Internal Report. UNEP, reference methods for marine pollution studies, No. 38.

Pekey, H., Karakas, D., Ayberk, S., Tolun, L., and Bakolu, M., (2004): Ecological risk assessment using trace elements from surface sediments of Ízmit Bay (Northeastern Marmara Sea) Turkey. Marine Pollution Bulletin, 48, 946-953.

Ramessur, RT. (2004): Statistical comparison and correlation of zinc and lead in estuarine sediments along the western coast of Mauritius. Environ Int, 30:1039-1044.

Rigollet, V., Sfriso, A., Marcomini, A., and Casabianka, M. L. (2004): Seasonal Evoluation of heavy metal concentrations in the surface sediments of two Mediterranean Zostera Marina LbedsatThau Lagoon (France) and Vinece Lagoon (Italy). 
Bioresources

Saad, S.D., Shreadah, M.A., (1984): The effect of sewage discharge on some chemical characteristics of seawater. VII JourneesEtud Pollutions, Lvcerene. CIESM, 81-90.

Saleh, S. M. K. (2006): Environmental assessment of heavy metals pollution in bottom sediments from the Gulf of Aden, Yemen. Ph. D. Thesis,Institute of Graduate Studies and Research, Alexandria University, Egypt.

Salem, M. S. Dalia, Azza Khaled | Ahmed El Nemr Amany El-Sikaily.(2014): Comprehensive risk assessment of heavy metals in surface sediments along the Egyptian Red Sea coast. Volume 40, Issue 4, January 2014, 349-362.
Tomolison, D. L., Wilson, J. G., Harris, C. R., and Jerrry, W. D. (1980): Metal accumulation rates in northwest Atlantic pelagic sediments. HelgolMeeresunters, vol. 33, pp. 535-

Villares, R., Puente, X. and Carballeira, A. (2003): Heavy metals in sandy sediments of the Rias (NW Spain). Environmental Monitoring and Assessment, 83, 129-144.

Yang, Y.; Chen, F.; Zhang, L.; Liu, J.; Wu, S. and Kang, M. (2012): Comprehensive assessment of heavy metal contamination in sediment of the Pearl River Estuary and adjacent shelf. Marine Pollution Bulletin, vol. 64, no. 9, pp. 1947-1955.

Zhang, W. G., Yu, L. Z., Lu, M., Simon, M. H. and Feng, H. (2007): Environ. Pollut., 147: 238-244.

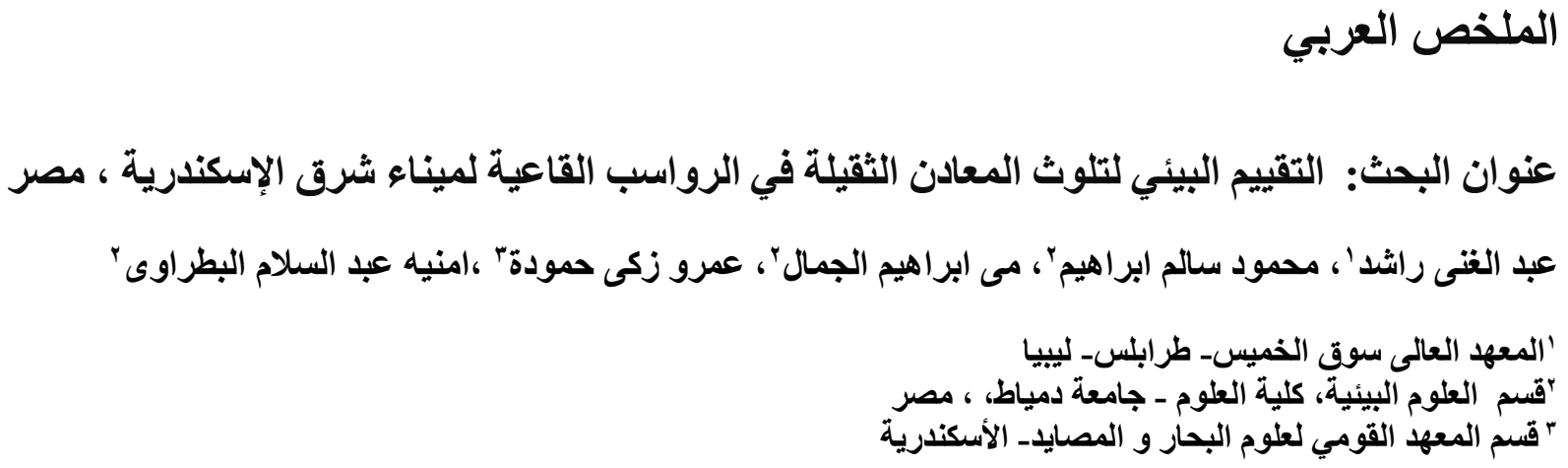

تم قياس تراكيز المعادن الثقيلة في رواسب ميناء شرق الإسكندرية الذي تم جمعه مرتين خلال عام

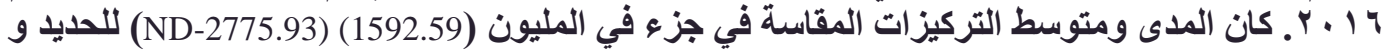

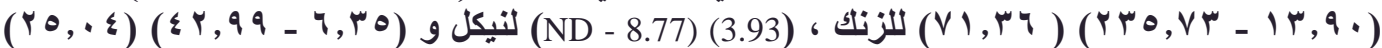

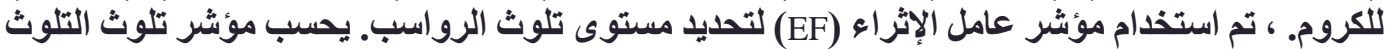

لجميع عينات الرسوبيات التي تقع في المصطلحات الثانية (PLI)

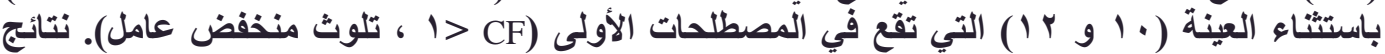

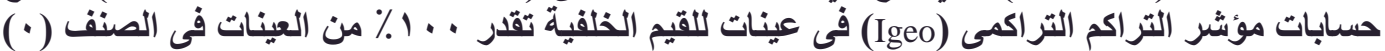

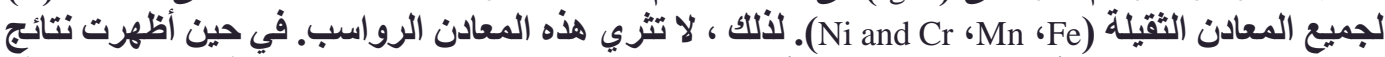

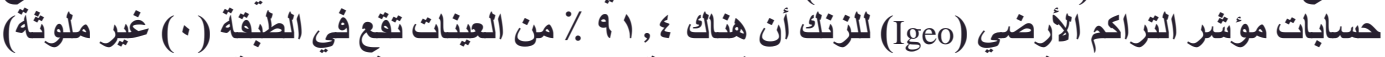

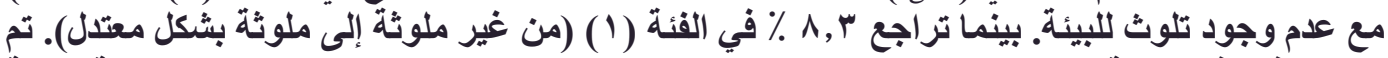

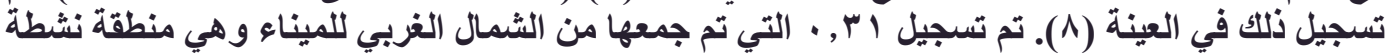

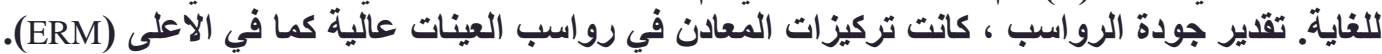

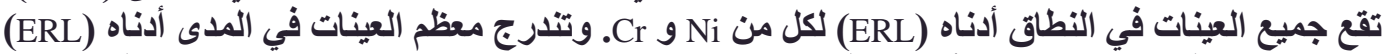

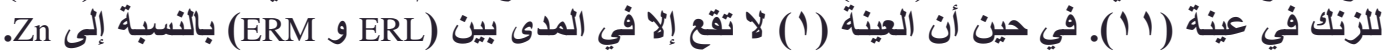

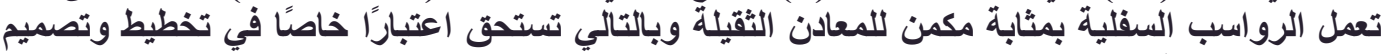

$$
\text { الار اسات البحثية للتلوث المائي. }
$$

